\title{
LINGKUNGAN KERJA TERHADAP KEPUASAN KERJA KARYAWAN FOOD AND BEVERAGE PRODUCT DEPARTMENT THE PAPANDAYAN HOTEL BANDUNG
}

\author{
Annisa Dwi Rachmawati, Gita Siswhara, Oman Sukirman \\ Program Studi Manajemen Industri Katering \\ Fakultas Pendidikan Ilmu Pengetahuan Sosial \\ Universitas Pendidikan Indonesia
}

annisadwi1805@yahoo.com

\begin{abstract}
Abstrak
Permasalah yang dikaji didalam penelitian ini adalah mengenai rendahnya kepuasan kerja karyawan Food and Beverage Product Department The Papandayan Hotel Bandung yang ditandai dengan tingginya tingkat turnover di dalam perusahaan. Permasalahan ini harus segera diatasi karena apabila tidak segera ditangani dapat menjadi penghambat bagi tercapainya tujuan The Papandayan Hotel Bandung.

Penelitian ini bertujuan untuk mengetahui gambaran mengenai lingkungan kerja karyawan, kepuasan kerja dan sejauh mana pengaruh lingkungan kerja terhadap kepuasan kerja karyawan Food and Beverage Product Department The Papandayan Hotel Bandung. Aspek yang diteliti meliputi dua hal yaitu lingkungan kerja dan kepuasan kerja karyawan.

Penelitian ini menggunakan metode deskriptif dan eksplanatif dengan populasi berjumlah 50 orang responden. Teknik analisis yang digunakan adalah koefisien korelasi pearson dan analisis regresi sederhana.

Hasil penelitian menunjukan bahwa lingkungan kerja dan kepuasan kerja karyawan Food and Beverage Product Department The Papandayan Hotel Bandung berada pada kategori sedang. Hasil perhitungan korelasi sebesar 0,631 artinya terdapat hubungan yang cukup tinggi antara lingkungan kerja dengan kepuasan kerja karyawan. Hasil perhitungan analisis regresi sederhana didapat persamaan $Y=10,267$ $+0,623 \mathrm{X}$ dan $\mathrm{KD}=39,87$ artinya pengaruh lingkungan kerja terhadap kepuasan kerja karyawan sebesar 39,87\% sedangkan sisanya 60,13\% dipengaruhi faktor yang tidak diteliti.

Saran yang diberikan sebaiknya perusahaan lebih memperhatikan lingkungan kerja baik fisik maupun non-fisik untuk meningkatkan kepuasan kerja karyawan karena lingkungan kerja memiliki pengaruh terhadap peningkatan kepuasan kerja karyawan.

Kata Kunci: Lingkungan Kerja, Kepuasan Kerja, The Papandayan Hotel

\section{Pendahuluan}

Perkembangan dibidang kepariwisataan tidak dapat dipisahkan dari objek wisatanya itu sendiri dan fasilitas-fasilitas pendukung yang tersedia. Maka pemerintah pada hal ini harus turut serta berperan dalam pengelolaan dan
\end{abstract}


pengembangan pariwisata sebagai industri yang ditangani secara profesional dan dikelola dalam skala departemen.

Semakin bertambahnya wisatawan yang datang ke Bandung dituntut pula perkembangan akomodasi yang menunjang pariwisata yang ada. Salah satunya adalah hotel. Hotel merupakan sarana tempat tinggal umum untuk wisatawan dengan memberikan pelayanan jasa kamar, penyedia makanan dan minuman serta akomodasi dengan syarat pembayaran. Hotel sangat dibutuhkan oleh para wisatawan, baik domestik maupun wisatawan mancanegara, oleh karena itu, hotel merupakan salah satu kunci pendukung bagi pengembangan pariwisata.

Wisatawan merupakan bagian yang tidak dapat dipisahkan dari dunia pariwisata. Semakin berkembangnya jaman banyak wisatawan yang mempunyai keinginan beragam mengenai hotel yang akan mereka pilih untuk tempat menginap. Fasilitas-fasilitas yang ada di dalam hotel akan menjadi pertimbangan tersendiri bagi para wisatawan.

Objek wisata dan fasilitas-fasilitas pendukung merupakan hal-hal yang dapat membangun industri pariwisata apabila dikelola baik oleh sumber daya manusia yang terampil dibidang ini. Permasalahan yang timbul disebuah perusahaan bukan hanya mengenai alat, produk ataupun mesin-mesin produksi. Sumber daya manusia yang ada juga dapat menjadi masalah dalam sebuah perusahaan, yang mampu menghambat perusahaan untuk mencapai tujuannya. Bahasan yang akan dibahas penulis adalah mengenai sumber daya manusia, khususnya karyawan Food and Beverage Product Department The Papandayan Hotel Bandung.

Setelah dilakukan survei pra-penelitian melalui kuesioner dan wawancara yang dilakukan oleh peneliti ditemukan bahwa kepuasan kerja karyawan Food and Beverage Product Department The Papandayan Hotel masih belum optimal atau dapat dikatakan rendah. Banyak faktor yang dapat mempengaruhi kepuasan kerja karyawan dan untuk lebih memperjelas mengenai kepuasan kerja karyawan dan faktor yang mempengaruhinya maka dilakukan penyebaran angket pra penelitian kepada 50 orang karyawan Food and Beverage Product Department The Papandayan Hotel Bandung.

Berdasarkan identifikasi masalah yang penulis temukan dan berdasarkan latar belakang di atas, penulis perlu melakukan penelitian untuk mencari solusi yang mengacu terhadap teori-teori yang ada mengenai "LINGKUNGAN KERJA TERHADAP KEPUASAN KERJA KARYAWAN FOOD AND BEVERAGE PRODUCT DEPARTMENT THE PAPANDAYAN HOTEL BANDUNG”

Berdasarkan uraian pada latar belakang, pokok permasalahan, dan judul penelitian maka dapat dirumuskan tujuan penelitian sebagai berikut :

1. Untuk memperoleh temuan mengenai lingkungan kerja pada bagian Food and Beverage Product Department The Papandayan Hotel Bandung.

2. Untuk memperoleh temuan mengenai kepuasan kerja karyawan Food and Beverage Product Department The Papandayan Hotel Bandung.

3. Untuk memperoleh temuan seberapa besar pengaruh lingkungan kerja terhadap kepuasan kerja karyawan Food and Beverage Product Department The Papandayan Hotel Bandung. 


\section{METODE PENELITIAN}

Penelitian ini menganalisis mengenai pengaruh lingkungan kerja terhadap kepuasan kerja karyawan Food and Beverage Product Department The Papandayan Hotel Bandung. Adapun yang menjadi variabel independent atau variabel bebas yaitu lingkungan kerja dan variabel dependent atau variabel terikat dari penelitian ini adalah kepuasan kerja. Variabel bebas (X) lingkungan kerja mempunyai dua indikator yaitu lingkungan kerja fisik (X1) dan lingkungan kerja non-fisik (X2). Subjek yang akan diteliti dalam penelitian ini adalah seluruh karyawan Food and Beverage Product Department The Papandayan Hotel yang berlokasi di Jalan Gatot Subroto Nomor 83 Bandung.

Berdasarkan variabel-variabel yang akan diteliti, maka penulis menggunakan jenis penelitian deskriptif dan eksplanasi. Penelitian deskriptif menurut Asep Hermawan (2009:84) dilakukan untuk menjelaskan karateristik berbagai variabel penelitian dalam situasi tertentu. Penelitian ini dapat pula disebut sebagai penelitian yang menjelaskan fenomena apa adanya. Penelitian deskriptif mengambil masalah atau memusatkan perhatian pada masalah-masalah aktual sebagaimana adanya pada saat penelitian dilaksanakan. Dengan melalui penelitian deskriptif, maka dapat diperoleh gambaran pengaruh mengenai lingkungan kerja dalam kaitannya dengan kepuasan kerja karyawan Food and Beverage Product Department The Papandayan Hotel Bandung.

Penelitian eksplanasi merupakan penelitian yang bertujuan untuk menjelaskan suatu generalisasi sampel terhadap populasinya atau menjelaskan hubungan, perbedaan atau pengaruh satu variabel dengan variabel yang lain. Maka secara eksplanasi seperti yang dijelaskan Burhan Bungin (2011:46), penelitian ini menguji kebenaran dari hipotesis yang didasarkan pada data penelitian di lapangan dimana penelitian ini akan diuji. Adapun permasalahan yang akan diuji adalah apakah faktor lingkungan kerja akan mempengaruhi kepuasan kerja karyawan Food and Beverage Product Department The Papandayan Hotel Bandung.

Penilitian ini menggunakan metode survei informasi dari seluruh populasi yang berjumlah 50 orang dan dikumpulkan secara empirik, dengan tujuan untuk mengetahui pendapat dari seluruh populasi terhadap objek yang sedang diteliti. Menurut Sugiyono (2012:11) metode survei adalah metode penelitian yang dilakukan pada populasi besar maupun kecil, tetapi data yang dipelajari adalah data dari sampel yang diambil dari populasi tersebut, sehingga ditemukan kejadian-kejadian relatif, distribusi, dan hubungan-hubungan antar variabel sosiologis maupun psikologis.

\section{HASIL DAN PEMBAHASAN PENELITIAN}

Hal yang dilakukan untuk mengetahui pengaruh lingkungan terhadap kepuasan kerja karyawan adalah dengan melakukan uji statistik yaitu dengan melakukan analisis koefisien korelasi pearson dan melakukan analisis regresi linier sederhana. Pengujian hipotesis yang telah dilakukan bertujuan untuk memperoleh kesimpulan bahwa lingkungan kerja di The Papandayan Hotel Bandung memberikan pengaruh positif terhadap kepuasan kerja karyawan Food and Beverage Product Department.

Hasil pengolahan dan perhitungan data diperoleh bahwa koefisien korelasi antara variabel lingkungan kerja $(\mathrm{X})$ dan variabel kepuasan kerja $(\mathrm{Y})$ yaitu sebesar 
0,631. Kemudian, diinterpretasikan ke dalam tabel interpretasi $\mathrm{r}$ dan ternyata 0,631 berada pada interval 0,600 - 0,800 yang termasuk ke dalam tingkat hubungan cukup tinggi. Jadi dapat disimpulkan bahwa terdapat hubungan yang cukup tinggi antara lingkungan kerja dan kepuasan kerja karyawan Food and Beverage Product Department The Papandayan Hotel Bandung.

Hasil perhitungan regresi linier sederhana diperoleh persamaan regresi linier lingkungan kerja atas kepuasan kerja yaitu $\mathrm{Y}=10,627+0,623 \mathrm{X}$. Hal ini berarti setiap perubahan satu satuan lingkungan kerja maka nilai kepuasan kerja berubah sebesar 0,623. Apabila ada peningkatan lingkungan kerja maka kepuasan kerja akan naik sebesar 0,623 dan apabila ada penurunan lingkungan kerja maka kepuasan kerja akan turun sebesar 0,623.

Selanjutnya dari hasil perhitungan data diperoleh koefisien determinasi yaitu $\mathrm{r}^{2}$ $\mathrm{x} 100 \%=(0,631)^{2} \times 100 \%=39,87 \%$. Hal ini menjelaskan bahwa pengaruh lingkungan kerja di The Papandayan Hotel terhadap kepuasan kerja karyawan Food and Beverage Product Department adalah sebesar 39,87\%. Sedangkan sisanya sebesar $60,13 \%$ dipengaruhi oleh variabel atau faktor lain yang tidak diteliti oleh penulis.

Perusahaan harus selalu dapat menciptakan lingkungan kerja yang sesuai dengan harapan karyawan. Dengan lingkungan kerja yang kondusif yang dilengkapi dengan fasilitas yang menunjang pekerjaan dan kondisi lingkungan kerja yang menyenangkan, maka akan didapati hasil kerja yang optimal karena karyawan dapat secara penuh berkonsentrasi dalam melaksanakan pekerjaannya. Sebaliknya apabila lingkungan kerja tidak kondusif dengan tidak disediakannya fasilitas-fasilitas pendukung yang menunjang pekerjaan dan suasana lingkungan kerja yang kurang menyenangkan akan mengakibatkan hasil kerja yang dicapai oleh karyawan tidak maksimal bahkan bisa saja menurun, karena para karyawan tidak dapat sepenuhnya berkonsentrasi terhadap pekerjaan atau dengan kata lain karyawan merasa terganggu dengan keadaan yang ada di sekitar mereka. Maka, apabila kondisi lingkungan kerja perusahaan sesuai dengan apa yang diharapkan oleh karyawan, karyawan akan bekerja dengan sungguh-sungguh karena semua harapan karyawan sesuai dengan apa yang diterima dalam kenyataannya, sehingga pada akhirnya dapat meningkatkan kepuasan kerja yang nantinya akan berdampak pada perusahaan itu sendiri. Kepuasan kerja karyawan merupakan kunci pendorong moral, kedisiplinan dan prestasi kerja karyawan dalam mendukung terwujudnya tujuan perusahaan (Hasibuan, 2007).

Berdasarkan hasil penelitian maka diketahui bahwa lingkungan kerja mampu meningkatkan kepuasan kerja pada karyawan Food and Beverage Product Department The Papandayan Hotel Bandung.

\section{SIMPULAN}

Gambaran lingkungan kerja pada The Papandayan Hotel Bandung yang terdiri dari lingkungan kerja fisik dan lingkungan kerja non fisik berada pada kategori sedang, dengan lingkungan kerja non fisik yang lebih baik dibandingkan lingkungan kerja fisik. 
Gambaran kepuasan kerja karyawan Food and Beverage Product Department The Papandayan Hotel Bandung diantaranya adalah loyalitas , produktif, kepeduliaan, kepercayaan dan komitmen berada dalam kategori sedang dengan kepedulian yang tinggi dibandingkan dengan keempat dimensi kepuasan kerja lainnya. Hal ini menunjukkan bahwa mayoritas karyawan Food and Beverage Product Department The Papandayan Hotel Bandung telah memiliki kepedulian yang tinggi terhadap hasil pekerjaannya.

Agar dapat meningkatkan kepuasan kerja melalui lingkungan kerja yang berkaitan dengan lingkungan kerja fisik, perusahaan perlu meninjau kembali upayaupaya yang harus dilakukan agar lingkungan kerja fisik sesuai dengan apa yang diinginkan karyawan. Hal ini dapat dilakukan dengan cara menambah fasilitas yang belum tersedia di lingkungan kerja dan perusahaan perlu memperhatikan kondisi peralatan kerja yang tersedia yaitu dengan selalu memperbaiki kondisi peralatan kerja secara cepat apabila terdapat peralatan yang rusak, sehingga tidak ada lagi pekerjaan yang tertunda karena kondisi peralatan kerja yang sering dalam keadaan tidak berfungsi dengan baik. Perusahaan juga perlu memperhatikan kondisi penempatan bangunan atau ruang kerja terhadap ruangan kerja lain yang terkait. Jarak dapur pastry yang jauh dengan bagian-bagian yang terkait seperti main kitchen, store, receiving, restaurant dan cake shop dapat menjadi sebuah hambatan bagi karyawan terutama karyawan pada bagian pastry and bakery section untuk bekerja secara optimal karena kondisi karyawan yang terlalu letih karena jarak untuk mencapai bagian-bagian tersebut terlalu jauh. Apabila perusahaan mampu dan situasinya memungkinkan. Maka, akan lebih baik untuk segera memindahkan bagian dapur pastry agar dekat dengan main kitchen, store, receiving, restaurant dan cake shop.

Untuk meningkatkan kepuasan kerja karyawan Food and Beverage Product Department The Papandayan Hotel Bandung, perusahaan dianggap perlu memperhatikan beberapan indikator yang mempengaruhinya. Hal tersebut dapat dilakukan dengan cara memberikan penghargaan atas setiap pekerjaan yang diselesaikan karyawan, agar tercipta kepuasan kerja dan pada akhirnya tingkat kepedulian karyawan terhadap kualitas kerjanya lebih tinggi. Salah satu contohnya adalah dengan memberikan penghargaan Employee of The Month kepada karyawan dengan prestasi terbaik.

\section{DAFTAR PUSTAKA}

\section{Sumber: Buku}

Alma, Buchari. 2009. Pengantar Bisnis (Edisi Revisi). Bandung: Alfabeta

Arikunto, Suharsimi. 2010. Prosedur Penelitian Suatu Pendekatan Praktik. Jakarta: Rineka Cipta

Bungin, Burhan. 2011. Metedologi Penelitian Kuantitatif. Jakarta: Kencana.

Dessler, Gary. 2006. Manajemen Sumber Daya Manusia Jilid I. Jakarta: PT Indeks

Hariandja, Marihot. T.E. 2009. Manajemen Sumber Daya Manusia Pengadaan, Pengembangan, Pengkompensasian, dan Peningkatan Produktivitas Pegawai. Jakarta: PT. Gramedia Widiasarana Indonesia.

Hasibuan, Malayu. 2008. Organisasi dan Motivasi. Jakarta: PT Bumi Aksara.

Hermawan, Asep. 2009. Penelitian Bisnis. Jakarta: PT Grasindo 
Ivancevich, J.M., Konopaske, Robert. Dan Matteson, M.T. 2007. Perilaku dan Manajemen Organisasi. Jakarta: Erlangga

Ivancevich, J. M. 2007. Human Resource Management (Internasional Edition). New York, Amerika: McGraw-Hill, Inc

Luthans, Fred. 2011. Organizational Behaviour: An Evidence Based Approach. New York, Amerika: McGraw-Hill, Inc

Mangkunegara, A.A. Anwar P. 2010. Perilaku dan Budaya Organisasi. Bandung: PT. Rafika Aditama

Nitisemito, Alex S. 2006. Manajemen Personalia: Manajemen Sumber Daya Manusia. Jakarta: Ghalia Indonesia

Panggabean, Mutiara S. 2004. Manajemen Sumber Daya Manusia. Bogor Selatan: PT Ghalia Indonesia

Robbins, S.P. dan Coulter, Mary. 2010. Manajemen Edisi Ke-10(Jilid 1). Jakarta: Erlangga

Robbins, S.P. dan Coulter, Mary. 2010. Manajemen Edisi Ke-10(Jilid 2). Jakarta: Erlangga

Robbins, S.P. dan Judge, T.A. 2008. Perilaku Organisasi. Jakarta: Salemba Empat

Sedarmayanti. 2001. Sumber Daya Manusia dan Produktivitas Kerja. Bandung: Mandar Maju

Sondang, P, Siagian. 2008. Manajemen Sumber Daya Manusia. Jakarta: Bumi Aksara Sugiyono. 2011. Metode Penelitian Kuantitatif Kualitatif dan R\&D. Bandung: Alfabeta

Sugiyono. 2012. Metode Penelitian Bisnis. Bandung: Alfabeta

Sulastyono, Agus. 2006. Manajemen Penyelenggaran Hotel. Bandung: Alfabeta

Suwatno dan Donni Juni Priansa. 2011. Manajemen SDM dalam Organisasi Publik dan Bisnis. Bandung: Alfabeta

Suwatno. 2011. Manajemen SDM. Bandung: Alfabeta

\section{Sumber: Jurnal}

Abidin, Zaenal dan Widagdo, Suharyo. 2009. Studi Literatur Tentang Lingkungan Kerja Fisik Perkantoran.

Igalens, Jacques and Roussel, Patrice. 1999. "A Study of the Relationships between Compensation Package, Work Motivation and Job Satisfaction Author(s)". Journal of Organizational Behavior. 20, (7), 1003-1025.

\section{Sumber: Skripsi}

Rosmini, Rossy. 2013. Pengaruh Kompensasi Dan Lingkungan Kerja Terhadap Kepuasan Kerja Karyawan Food and Beverage Department The Jayakarta Bandung Suite Hotel and Spa. Skripsi pada Fakultas Pendidikan Ilmu Sosial-Manajemen Industri Katering.

Yunanda, Mega, Arum. 2012. Pengaruh Lingkungan Kerja Terhadap Kepuasan Kerja dan Kinerja Karyawan (Studi Pada Perum Jasa Tirta I Malang Bagian Laboratorium Kualitas Air). Skripsi pada Fakultas Ekonomi dan Bisnis Universitas Brawijaya.

Silviana, Regina. 2013. Pengaruh Lingkungan Kerja Terhadap Kepuasan Kerja Karyawan Bank BJB Cabang Sukajadi Bandung. Skripsi pada Fakultas Pendidikan Ekonomi dan Bisnis Universitas Pendidikan Indonesia. 
Ramadhani, Ayu, Anisa. 2013. Pengaruh Kompensasi Terhadap Moyivasi Kerja Di PT Pos Indonesia (Persero) Bandung. Skripsi pada Fakultas Pendidikan Ekonomi dan Bisnis Universitas Pendidikan Indonesia. 